\title{
Para quê, para quem, como? \\ Alguns desafios do cotidiano da pesquisa em serviço social
}

\author{
What for, for whom, how? Some dally challenges \\ of the research in Social Services
}

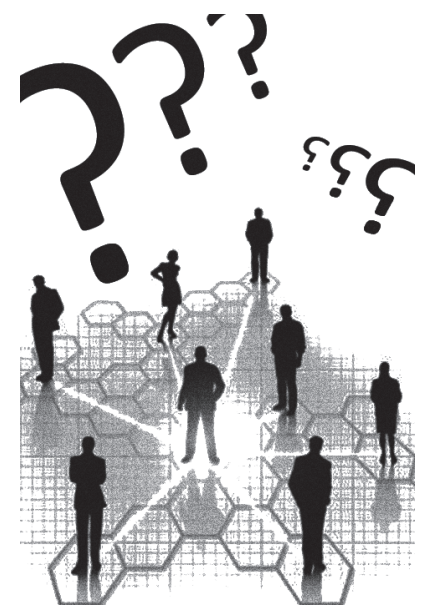

\author{
Carlos Antônio de Souza Moraes* \\ Denise Chrysóstomo de Moura Juncá** \\ Katarine de Sá Santos ${ }^{* *}$
}

\begin{abstract}
Resumo: Para quê, para quem e como pesquisamos? Estas são as indagações centrais deste artigo. Seu objetivo é discutir alguns desafios que transitam no cotidiano da pesquisa, bem como apresentar algumas ferramentas que propomos para a condução de tal processo, no contexto da formação profissional em Serviço Social. Defendemos o reconhecimento do exercício da pesquisa como estratégia de conhecimento e ação e, portanto, como dimensão constitutiva do trabalho do assistente social, ressaltando que tão importantes quanto as descobertas no campo do saber, são as estratégias de intervenção social a elas articuladas.
\end{abstract}

Palavras-chave: Pesquisa. Exercício profissional. Serviço Social.

\begin{abstract}
What for, for whom and how do we research? These are the central issues of this article. Its purpose is to discuss challenges found in the daily research and to present some tools to conduct this process in the context of professional training in Social Services. We support the recognition of conducting research as a strategy for knowledge and action and thus as the constitutive dimension
\end{abstract}

* Assistente social, mestre em Política Social, professor assistente do Instituto de Ciências da Sociedade e Desenvolvimento Regional - Universidade Federal Fluminense - Campos dos Goytacazes/RJ Brasil. E-mail: as.carlosmoraes@gmail.com.

** Assistente social, doutora em Saúde Pública, professora associada do Instituto de Ciências da Sociedade e Desenvolvimento Regional — Universidade Federal Fluminense — Campos dos Goytacazes/RJ Brasil.E-mail: denise@ censanet.com.br.

*** Assistente social, mestre em Planejamento Regional e Gestão de Cidades, professora do Curso de Pós-graduação em Saúde Coletiva da Universidade Salgado de Oliveira e da Escola Técnica Estadual Agrícola Antônio Sarlo — Campos dos Goytacazes/RJ — Brasil. E-mail: katarine.santos0@ gmail.com. 
of the social worker's job. We point out that the discoveries in the field of knowledge are as important as the social intervention strategies that are related to such discoveries.

Keywords: Research. Professional practice. Social Services.

\section{Questões introdutórias}

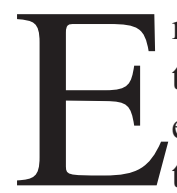

m nossa experiência profissional, não raras vezes ouvimos depoimentos de colegas assistentes sociais defendendo, com veemência, o exercício da pesquisa em seu cotidiano institucional. Entretanto, também, não foram raros os momentos em que verificamos que esse discurso nem sempre alcançava a prática.

Falta de tempo, excesso de atribuições, pouca disponibilidade de pessoal, ausência de recursos... Estas eram as justificativas mais usadas. A seu lado surgia uma outra questão: a associação da prática da investigação a um mundo de regras tidas como sofisticadas, destacando-se falas que consideravam, equivocadamente, que pesquisa só se faz na universidade, é coisa para "intelectual", contrapondo-se aos que estão diretamente conectados à realidade social.

Mesmo com tantas restrições, nos deparamos, também, com situações em que a pesquisa era, obrigatoriamente, incorporada a momentos do cotidiano de alguns. Falamos aqui, principalmente, dos profissionais que precisavam construir e realizar projetos, face às exigências dos cursos de pós-graduação que frequentavam. Nesses casos, por vezes predominava uma concepção onde falar em pesquisa era, sobretudo, pensar em normas e prazos, um peso a carregar, uma obrigação a cumprir, um sacrifício a fazer. Uma crônica de Mário Prata ilustra bem a situação:

escrever uma tese é quase um voto de pobreza que a pessoa se autodecreta. $\mathrm{O}$ mundo para, o dinheiro entra apertado, os filhos são abandonados, o marido que se vire. Estou acabando a tese. Essa frase significa que a pessoa vai sair do mundo. Não por uns dias, mas anos. Tem gente que nunca mais volta. (Prata, ${ }^{1}$ 1998, apud Freitas, 2002, p. 10)

1. O Estado de São Paulo, 7/10/1998. 
Exercitando ou não um processo de investigação, o que parecia prevalecer, nesses casos, era certa elitização ou burocratização da pesquisa ou, ainda pior, o aprisionamento, o enquadramento de uma prática que nasceu para ser ousada, desafiadora, saborosa.

Certamente não defendemos a banalização da pesquisa ou o enfraquecimento do rigor científico. Da mesma forma, não desconhecemos o papel da universidade na produção do conhecimento, ou mesmo a validade e a seriedade dos inúmeros projetos que são desenvolvidos intra e extramuros. Mas também precisamos pensar melhor o sentido da pesquisa. Quer dizer, um ponto fundamental é recuperar o significado da prática da pesquisa em nosso cotidiano. Prática que, a nosso ver, deve ser artesanalmente construída (Mills, 1982, p. 211), de forma apaixonada e vibrante, desenhando problematizações e encarando desafios. Prática com fome de descobertas, combinando razão e sensibilidade, rigor e criatividade, ciência e arte, conhecimento e ação. Prática que comemora os "achados" do processo de investigação, mas que com ponderação e humildade desconfia desses "achados" e quer avançar sempre mais, valorizando os sujeitos com os quais se relaciona.

Humberto Eco (1977, p. 169) nos diz que o importante é fazer as coisas com gosto, é assumir a pesquisa como um desafio, uma caça ao tesouro. Esta é uma perspectiva que não podemos esquecer e, em nossa concepção, está diretamente associada a algumas indagações: para quê pesquisamos? Para quem? Como?

Muitos são os dilemas e interrogações a ser enfrentados na prática da pesquisa. Alguns deles serão aqui abordados, e nossa intenção é tão somente compartilhar inquietações, partindo da premissa de que a atitude investigativa é uma dimensão inseparável do processo de formação profissional e do cotidiano do Serviço Social, e que não se trata apenas de avançar no campo do conhecimento. É fundamental garantir a unidade entre o saber, o fazer, o saber fazer e o refazer, ancorados em uma clara compreensão do tipo de sociedade que queremos construir.

\section{Alguns sentidos da pesquisa: usos e abusos}

Diariamente, algumas reportagens dos jornais e revistas divulgam as mais diferentes descobertas. São novas drogas que emagrecem com rapidez, cremes 
que acabam com as rugas; produtos naturais que fazem milagres com o colesterol, copos de vinho que previnem problemas cardíacos, doenças que são típicas de alguns tipos de ocupação profissional, o papel do trabalho informal no sustento das famílias, a relação do desemprego com a violência doméstica, o significado dos programas de transferência de renda na constituição de um novo perfil de consumo das famílias brasileiras...

Não se trata aqui de, simplesmente, questionar os temas em discussão ou duvidar de seus resultados. A questão é: que tipo de resultado as pesquisas produzem? A quem interessam estes resultados? Que uso se faz deles? Em última análise, qual é o sentido da pesquisa? Para quê e para quem se faz pesquisa? Como se pesquisa?

Sem ignorar as dimensões teórico-metodológicas, imprescindíveis em um processo de investigação científica, o que está em discussão, em um primeiro momento, é uma questão ética. Questão que, como nos lembra Rubem Alves [1999] causa profunda estranheza em decorrência da ideologia silenciosa que acompanha a prática científica, uma vez que a mesma parte da premissa, não crítica, de que "todo conhecimento é bom".

Ao se perguntar "pesquisa: para quê?", o autor afirma que não há um cheiro autoritário, pragmático, imediatista ou comercial em sua indagação. O que ele problematiza é a função social do conhecimento produzido, o resultado social das investigações dos pesquisadores.

Alves destaca, assim, a importância de considerarmos a que e a quem se destina tal conhecimento e de que forma ele pode ser apropriado por tais sujeitos, analisando, também, que

o estilo determina quem irá usar a ferramenta. É inútil criar binóculos e microscópios para os cegos. Sua precisão de nada vale. Ao construir um binóculo ou microscópio, já tomei uma decisão: estas ferramentas só poderão ser usadas por pessoas que podem ver. Os conceitos que empregamos, as categorias e o estilo que usamos, de forma análoga, funcionam de forma determinista: eles selecionam, previamente, aqueles que poderão entendê-las e, portanto, usá-las. ([1999], p. 3)

A linguagem é discutida, pelo autor, como uma "ferramenta para interferência direta num mundo social" e, portanto, não pode ficar aprisionada no seio da comunidade científica; ela precisa ser um canal de interlocução, já que produzimos "um conhecimento que é necessário a alguém". 
Com tal preocupação, não podemos ignorar, também, alguns aspectos analisados no livro $O$ fundo falso das pesquisas: a ciência das verdades torcidas (1996). Nele, Cynthia Crossen salienta, por exemplo, de que forma as pesquisas, e mais particularmente os números, vêm se configurando como poderosos elementos de persuasão, uma vez que agregam credibilidade a uma informação, dando-lhe um senso de racionalidade. Para ela, sob o disfarce de ciência objetiva, o que pode acontecer é a "corrupção da informação", já que as conclusões de muitas pesquisas podem refletir, acima de tudo, os interesses de quem as encomendam.

A autora se refere à pseudociência e sua ação, associando uma tentativa de legitimação do conhecimento, por meio da propaganda que é feita, informando que muitas pesquisas não passam de meros levantamentos de dados e tratam de temáticas banais. Entretanto, elas têm aparência de científicas em razão da forma como os resultados são apresentados, recorrendo a percentuais, margens de erro, significações estatísticas.

Um dos aspectos que discute é, portanto, o risco da subserviência da pesquisa, o seu uso face à necessidade de dar maior credibilidade a um resultado já esperado, enfatizando a manipulação dos números e sua influência no cotidiano dos indivíduos:

Cada vez mais, as informações que usamos para comprar, escolher, aconselhar, absolver e medicar vêm sendo criadas, não para expandir nosso conhecimento, mas para promover um produto, ou para promover uma causa. Se o resultado da pesquisa for contrário ao esperado pelos patrocinadores, ele certamente não será divulgado [...] Em supermercados e drogarias, as pesquisas atuam como nossos médicos, pais ou farmacêuticos; nas salas de tribunais, os estudos e pesquisas são hoje os advogados; são as pesquisas que acabam ditando a legislação e as práticas comerciais e de marketing. Na opinião pública, dados e pesquisas significam uma mudança de rumo, no qual as crenças pessoais são substituídas pelas crenças de umas poucas centenas de estranhos. (Crossen, 1996, p. 10)

Desenvolvendo reflexões semelhantes, Aquino (2001, p.12) destaca que "encontramos números que são verdadeiros exercícios do livre pensar, percentagens que se arvoram de senhoras absolutas das realidades sociais, econômicas, políticas, demográfica e por aí vai o festim”. O pior é que algumas dessas “pérolas", como denomina o autor, são usadas para justificar condutas e decisões 
espúrias, ou mesmo "para consolidar atitudes, referendar pleitos, enfim, se sobrepor ao todo, via de regra carente de informações verídicas e confiáveis".

A questão não é ignorar ou menosprezar o valor dos dados estatísticos que usualmente acompanham as pesquisas. Não podemos esquecer sua importância ao lembrarmos, por exemplo, que nos anos 1990 alguns estudos sobre a longevidade já indicavam o percentual significativo de crescimento que era esperado, no número dos idosos no país, no início do novo século. Uma avaliação prévia de tal tendência não era fundamental para o planejamento de políticas sociais que atendessem aos interesses e necessidades dessa população? Como ignorar, também, as valiosas indicações fornecidas pelos censos realizados periodicamente pelo IBGE? Elas não são significativas tanto para elaborarmos diagnósticos socioeconômico-culturais, quanto para anteciparmos tendências e projetarmos ações em nossa sociedade?

O problema não está, portanto, na pesquisa propriamente dita, mas no uso indiscriminado de tal termo. Da mesma forma, o problema não está nos números, mas no modo como são produzidos e no uso que se faz deles. Não estamos retomando a velha dicotomia quantitativo versus qualitativo. $\mathrm{O}$ que queremos destacar é, de um lado, a necessária observação dos procedimentos utilizados para sua produção; e, de outro, as análises, devidamente sustentadas, de seus possíveis significados, no contexto de uma sociedade que tem uma história, que pulsa a cada dia para várias direções, por vezes, contraditórias.

Mais que isso, cabe questionar, novamente, a finalidade da produção de tantos dados. Podemos aqui lembrar que muito já se sabe sobre a pobreza no Brasil. Independente do conceito de pobreza adotado, inúmeros são os dados disponíveis. E nos perguntamos: e daí? Em que tais dados estão efetivamente contribuindo para a construção de um outro cenário no país? É possível não considerar as dimensões éticas, políticas e culturais contidas em um processo de conhecimento?

Retomando nosso cotidiano profissional, vemos facilmente como colecionamos dados sobre os nossos chamados usuários: sexo, faixa etária, profissão, composição familiar, condições habitacionais, escolaridade... Dados que classificam, rotulam e correm o risco de ficar isolados em cadastros, arquivos ou relatórios.

Se é certo que tais dados permitem uma primeira identificação dos usuários, propiciando ou não sua inclusão nos programas sociais e/ou ações institucionais existentes, é certo também que não basta juntar informações sem problematizar 
suas causas e possíveis significados, bem como sem analisar alternativas de ação. Da mesma forma, não basta nos cercarmos de tantos métodos e técnicas, esquecendo-nos da complexidade da produção do conhecimento, da ação política que tal processo pode envolver, do necessário protagonismo dos sujeitos, pesquisadores e pesquisados, em que "o desafio é tecer uma rede interpretativa onde o fenômeno estudado possa ser compreendido como parte de um universo e, ao mesmo tempo, um universo à parte" (Barbiani, 2004, p. 1).

Se reconhecemos que o ato do conhecimento configura uma "difícil travessia do singular ao particular, mediado pelo universal, imergindo numa realidade em constante movimento, sem saber, ao certo, onde se chegará" (idem), estamos admitindo o movimento de ordem-desordem-organização de que nos fala Morin (2001, p. 564). Admitimos também, como Barbiani (2004, p. 2), a importância do entrecruzamento de múltiplas vozes, temporalidades e movimentos. Recorrendo a Denzin e Lincoln (2000, p. 2), a autora destaca, ainda, que:

o pesquisador situado aproxima-se do mundo com um conjunto de ideias (ontologia, que se preocupa em entender o que pode ser conhecido), com um conjunto de conceitos (epistemologia, como se pode conhecer o mundo) através de maneiras específicas (metodologia e análise, como se obtém o conhecimento) [...]. Essas dimensões (e suas necessárias definições) configuram o paradigma interpretativo que guiará a ação investigativa, ainda que não esteja completamente explícito para o próprio pesquisador. Esse paradigma é constituído por diversas premissas, crenças e saberes que direcionam as respostas do pesquisador sobre: a natureza da realidade e dos sujeitos que a compõem; da sua relação com o conhecimento e da forma como se pode conhecer o mundo.

Com tais considerações, queremos reforçar nossa concepção de pesquisa, onde há um lugar garantido para a indagação inacabada, para movimentos de aproximação sucessiva, onde teoria e dados dialogam, permanentemente, enfatizando, como Demo (1991, p. 16, passim) que não se trata apenas de busca de conhecimento, mas,

Igualmente, como atitude política, sem reducionismo e embaralhamento, num todo só dialético [...] atitude processual de investigação do desconhecido e dos limites que a natureza e a sociedade nos impõem [...]. Pesquisa é descoberta da realidade [...]. É diálogo inteligente com a realidade [...]. Pesquisar, assim, é sempre também dialogar, no sentido específico de produzir conhecimento do 
outro para si, e de si para o outro, dentro de um contexto comunicativo nunca de todo devassável e que sempre pode ir a pique [...]. Pesquisa é sempre também fenômeno político [...] pesquisar somente para saber já seria proposta alienante, porque desencarna a pesquisa da sua face inserida na realidade histórica.

Cabe, portanto, reconhecer que estamos diante de um processo complexo, a ser conduzido de forma cuidadosa e criteriosa, comportando não só um olhar que indaga e quer saber, mas também aquele que se compromete e quer fazer algo, o que, no caso do Serviço Social, está afinado com a ultrapassagem do imediatismo e a sacralização do exercício profissional, retendo o desafio de operacionalizar seu projeto ético-político.

\section{Familiaridade e estranhamento}

Reproduzimos, a seguir, o poema "Ver vendo", de Otto Lara Rezende, para destacar um segundo ponto que queremos focalizar: a familiaridade e o desafio do estranhamento no processo de produção de conhecimento.

De tanto ver, a gente banaliza o olhar - vê... não vendo.

Experimente ver, pela primeira vez, o que você vê todo dia sem ver.

Parece fácil, mas não é: o que nos cerca, o que nos é

Familiar, já não desperta curiosidade.

O campo visual da nossa retina é como um vazio.

Você sai todo dia, por exemplo, pela mesma porta.

Se alguém the perguntar o que você vê no caminho, você não sabe.

De tanto ver, você banaliza o olhar. Sei de um profissional que.

Passou 32 anos a fio pelo mesmo hall do prédio do seu escritório.

Lá estava sempre, pontualíssimo, o porteiro. Dava-lhe bom dia e,

Às vezes, lhe passava um recado ou uma correspondência.

Um dia o porteiro faleceu. Como era ele? Sua cara? Sua voz?

Como se vestia? Não fazia a mínima ideia.

Em 32 anos nunca conseguiu vê-lo.

Para ser notado, o porteiro teve que morrer.

Se, um dia, em seu lugar estivesse uma girafa cumprindo o rito,

Pode ser, também, que ninguém desse por sua ausência. 
O hábito suja os olhos e baixa a voltagem. Mas há sempre

O que ver: gente, coisas, bichos. E vemos? Não, não vemos.

Uma criança vê o que um adulto não vê. Tem olhos atentos e limpos

Para o espetáculo do mundo. O poeta é capaz de ver pela primeira

Vez o que, de tão visto, ninguém vê. Há pai que raramente vê o

Próprio filho. Marido que nunca viu a própria mulher.

Nossos olhos se gastam no dia a dia, opacos.

... é por aí que se instala no coração o monstro da indiferença.

Tal poema nos remete a algumas indagações: o que vemos, o que deixamos de ver em nosso cotidiano? Que dimensões este ver deve assumir em nossa prática profissional?

É em Lefebvre (1991, p. 44) que encontramos pistas para caminharmos, quando ele analisa a questão de se "revelar a riqueza escondida sob a aparente pobreza do cotidiano, descobrir a profundeza sob a trivialidade, atingir o extraordinário do ordinário". Aqui parece encontrar-se um desafio. Desafio que nem sempre assumimos, em nome de uma suposta experiência acumulada durante os anos de trabalho.

Se não há como retirar o valor da experiência empírica e do saber que pode ser acumulado através dos anos, uma coisa não deve ser esquecida: a experiência pode cegar, pode dificultar novas percepções, novas análises, novas buscas de relações, limitando, consequentemente, o processo de reconstrução permanente, tão importante para a profissão.

Não raras vezes ouvimos o assistente social dizer que, após tanto tempo de trabalho em dada realidade, ele já possui um amplo conhecimento sobre ela. Seu problema, portanto, não é a falta de conhecimento, mas sim de condições objetivas favoráveis para realizar seus inúmeros projetos. Mas aí perguntamos: o que realmente ele sabe? Em que bases tal saber foi construído? Esse profissional não caiu em uma armadilha ao confiar em excesso em sua experiência profissional, deixando de trilhar o caminho da crítica, das aproximações sucessivas, das sínteses provisórias para a construção sustentada de um outro conhecimento?

Por intermédio da história da profissão, estamos constantemente nos referindo a estudos, diagnósticos, leituras de realidade, análises de conjuntura, mudando nomenclaturas, mas parecendo sempre valorizar uma postura inves- 
tigativa capaz de dar sustentação a nosso exercício profissional. Entretanto, não estamos naturalizando esse cotidiano? Não seria preciso assumirmos a postura de estranharmos o que parece tão conhecido? $\mathrm{O}$ estranhamento não seria o caminho mais adequado para a construção de uma experiência de conhecimento, entendida como complexa e sempre inacabada?

Citando estudos antropológicos de Da Matta (1978), Gilberto Velho (1978, p. 39) afirma: "O que sempre vemos e encontramos pode ser familiar, mas não é necessariamente conhecido e o que não vemos e encontramos pode ser exótico mas, até certo ponto conhecido" (grifos do autor). E o autor continua:

Dispomos de um mapa que nos familiariza com os cenários e situações sociais de nosso cotidiano, dando nome, lugar e posição aos indivíduos. Isto, no entanto, não significa que conhecemos o ponto de vista e a visão de mundo dos diferentes atores em uma situação social, nem as regras que estão por detrás dessas interações [...]. Posso estar acostumado [...] com uma certa paisagem social, onde a disposição dos atores me é familiar, a hierarquia e a distribuição de poder permitem-me fixar, grosso modo, os indivíduos em categorias mais amplas. No entanto, isto não significa que eu compreenda a lógica de suas relações. O meu conhecimento pode estar seriamente comprometido pela rotina, hábitos, esteriótipos. (Idem, p. 40)

Não se trata, como Velho acrescenta, de proclamar a "falência do rigor científico", mas sim de assumir a importância de percebê-lo, dentro de um contexto de objetividade relativa, o que nos remete à questão da subjetividade, sempre presente em processos de investigação, e à impossibilidade de resultados imparciais ou neutros.

Da mesma forma que não podemos abrir mão de eixos teóricos em uma pesquisa, não podemos ignorar que as interpretações do pesquisador (no caso que ora particularizamos, os assistentes sociais) precisam ser sempre revistas e confrontadas. Embora a familiaridade traduza um tipo de apreensão da realidade e possa contribuir para a construção de um conhecimento científico, ela não é sinônimo desse conhecimento.

Da mesma forma que Iamamoto (1998, p. 56), reconhecemos a pesquisa como uma dimensão integrante do exercício profissional dos assistentes sociais, como "uma condição para se formular respostas capazes de impulsionar a elaboração de propostas profissionais que tenham efetividade e permitam atribuir materialidade aos princípios ético-políticos norteadores do projeto profissional”. 
Entretanto, para que tal postura se efetive, precisamos estranhar mais o que nos parece tão familiar e nos familiarizarmos mais com aquilo que ainda é, sem dúvida, estranho.

Para tanto, um importante caminho a ser trilhado é, sem dúvida, o que nos sugere Martinelli (2005, p. 10): "pesquisar na perspectiva qualitativa, e sempre em articulação com a pesquisa quantitativa" ou seja, "contemplar de modo pacientemente impaciente o que se pretende pesquisar", exercitando "o olhar rigoroso, crítico, atento", buscando "o desvendamento crítico da realidade em análise, com vistas a uma intervenção mais qualificada".

Com tais referências, precisamos, ainda, lembrar que não lidamos com um homem abstrato, mas sim com um sujeito que tem história, relações, vínculos... Sujeito que já foi reduzido à condição de "cliente" desajustado e disfuncional ao sistema, mas que hoje transita por outras situações e com outra postura. Como nos lembra Faleiros (1996, p. 14):

Os atores sociais com os quais tradicionalmente tem trabalhado o Serviço Social também vêm mudando. Os pobres, as mulheres, os doentes, os idosos, as crianças, os adolescentes que constituem os usuários dos serviços sociais estão se constituindo como sujeitos políticos, como cidadãos, participantes de pequenos e grandes movimentos específicos de sua categoria, diversificando seu processo de inserção social, mas também consolidando-se como consumidores individuais de serviços sociais. Os movimentos sociais vão mudando no processo de sua estruturação interna, de suas estratégias, de seus resultados. Hoje, por exemplo, o movimento de mulheres assumiu dimensões impensadas no início do século, e se o movimento sindical perdeu fôlego e a importância então adquirida, não significa seu desaparecimento. Os movimentos de categorias específicas como homossexuais, negros, se tornaram mais importantes, enquanto houve um recuo dos movimentos localizados geograficamente por bairros. Os movimentos étnico-culturais assumiram formas mais visíveis e as organizações não governamentais assumiram papéis mais significativos, tanto na defesa de direitos como na prestação de serviços, seja à sombra do Estado, em lugar dele, ou em oposição a ele.

Aqui, não cabe ignorar a prática cotidiana e o lugar da experiência. Mas não cabe também ignorar a necessidade de "trabalhar a partir de uma proximidade crítica com os sujeitos", recorrendo ao diálogo pela via interdisciplinar e tendo, sempre, no "horizonte, o valor social da pesquisa, seu retorno ao campo de intervenção e aos sujeitos que dela participaram" (Martinelli, 2005, p. 10). 


\section{Projetos de pesquisa: ferramentas em discussão}

Os desafios que pretendemos focalizar neste texto envolvem, ainda, um outro ponto: o planejamento de uma pesquisa com viés predominantemente qualitativo. Reconhecemos a existência de discussões, ${ }^{2}$ englobando, de um lado, os que se posicionam claramente favoráveis à estruturação prévia de um processo de investigação, por meio da elaboração de um cuidadoso e detalhado projeto de pesquisa; de outro há, porém, os que defendem um mínimo de estruturação, indicando que tanto o foco da pesquisa quanto seu desenho e categorias teóricas devem ser definidos no decorrer do processo.

Não pretendemos entrar nessa discussão, entendendo que diversas variáveis devem ser levadas em conta antes de o pesquisador decidir a postura a adotar. Reconhecemos, contudo, que em muitas situações do cotidiano do assistente social surgem situações onde há exigências para a apresentação de tais projetos.

Particularizando o campo onde atuamos - a docência —, nos deparamos ainda com o debate da pesquisa no contexto curricular, sendo necessário introduzir os alunos de graduação no processo de debate sobre a construção de conhecimento, envolvendo, inclusive exercícios preliminares de pesquisa, seja em sala de aula, seja em situações relacionadas ao estágio supervisionado ou aos trabalhos finais de curso.

Recorrendo à experiência que temos acumulado, observando as dificuldades que enfrentam e as inúmeras dúvidas que levantam, optamos então por elaborar uma ferramenta com intuito de auxiliar tal processo e, portanto, tendo fins didáticos.

Esta opção não intenciona apresentar um roteiro ou modelo a ser rigorosamente seguido. Ao contrário, o que se pretende é trabalhar com uma proposta simples, que indique alguns movimentos iniciais e seu aprofundamento e detalhamento progressivo. Tais movimentos são discutidos e construídos pelos alunos, sob supervisão de seus professores, culminando com o recorte de um objeto de estudo, junto com as escolhas em termos dos eixos de análise e desenho que o mesmo vai assumir.

São cinco ferramentas que se inter-relacionam, mas são apresentadas e trabalhadas, distintamente, a partir do desafio que cada uma contém. Os quadros

2. Ver Alves-Mazzotti e Gewandsznajder, 1998. 
que se seguem ilustram nossa proposta, indicando os passos iniciais, as possíveis indagações a serem formuladas e as respostas preliminares elaboradas pelos pesquisadores. Tal processo permite que seja feito um mapeamento inicial do que se pretende, sinalizando elementos para a redação posterior do projeto propriamente dito.

A Ferramenta 1: em busca de um tema decorre de algumas perguntas que ouvimos inúmeras vezes: de onde surge um tema de pesquisa? O que devo fazer para escolher um assunto para investigar? Com os passos indicados, nossa intenção é provocar observações iniciais, listando possíveis áreas de interesse, fenômenos que chamam a atenção, algumas variáveis que os mesmos admitem, configurando uma fase que podemos denominar de preparatória para a condução do projeto. O último passo constitui a seleção de um tema provável, ainda em estado bruto, a ser problematizado e delimitado na Ferramenta 2.

\section{FERRAMENTA 1}

Em busca de um tema

\begin{tabular}{|c|c|c|}
\hline PASSO & INDAGAÇÃO & $\begin{array}{c}\text { RESPOSTA } \\
\text { PRELIMINAR }\end{array}$ \\
\hline $\begin{array}{l}\text { Identificação do cenário de } \\
\text { discussão/atuação }\end{array}$ & $\begin{array}{l}\text { Em que campo de conhecimento/atuação } \\
\text { profissional estou inserido? }\end{array}$ & \\
\hline $\begin{array}{l}\text { Enumeração de temáticas } \\
\text { presentes no cenário identificado }\end{array}$ & $\begin{array}{l}\text { Que fenômenos e/ou problemas identifico } \\
\text { nesse cenário? }\end{array}$ & \\
\hline $\begin{array}{l}\text { Seleção de } u m \text { tema (a partir da } \\
\text { enumeração anterior) }\end{array}$ & $\begin{array}{l}\text { Que fenômeno e/ou problema desperta } \\
\text { meu interesse/curiosidade? }\end{array}$ & \\
\hline Identificação de variáveis & $\begin{array}{l}\text { Que variáveis estão presentes no contexto } \\
\text { do fenômeno e/ou problema de meu } \\
\text { interesse? }\end{array}$ & \\
\hline Escolha de um possível tema & $\begin{array}{l}\text { Que tema seleciono para desenvolver } \\
\text { minha pesquisa? }\end{array}$ & \\
\hline
\end{tabular}


Recorte de um objeto de pesquisa é a proposta da Ferramenta 2. Trata-se de um passo onde diversos movimentos são feitos no sentido da delimitação do tema. Aqui mergulhamos na fase exploratória de uma pesquisa, buscando maior aproximação com o campo onde nos inserimos, realizando revisão de literatura, discutindo a relevância social e científica do que queremos estudar, definindo nossos objetivos, enunciando nosso objeto com clareza.

\title{
FERRAMENTA 2
}

Recorte de um objeto $\rightarrow$ moldura

\begin{abstract}
DESAFIO: "A primeira tarefa que se impõe, portanto, é ver o problema com clareza [...]. Quem não diz com clareza, não está vendo com clareza [...]. Enunciar com clareza o problema é indicar, antes de mais nada, de que partes ele se compõe" (Alves, 1966, p. 29).
\end{abstract}

\begin{tabular}{|c|c|c|}
\hline PASSO & INDAGAÇÃO & $\begin{array}{l}\text { RESPOSTA } \\
\text { PRELIMINAR }\end{array}$ \\
\hline Delimitação preliminar do tema & $\begin{array}{l}\text { Em que contexto e com quais sujeitos } \\
\text { quero desenvolver meu tema? } \\
\text { Que pergunta faço a meu tema? }\end{array}$ & \\
\hline $\begin{array}{l}\text { Realização de uma revisão de } \\
\text { literatura — inventário }\end{array}$ & $\begin{array}{l}\text { O que já se produziu sobre este problema? } \\
\text { Que autores já discutiram este tema? Há } \\
\text { consensos? Controvérsias? Lacunas? }\end{array}$ & \\
\hline $\begin{array}{l}\text { Discussão da justificativa, } \\
\text { viabilidade e relevância social e } \\
\text { científica }\end{array}$ & $\begin{array}{l}\text { Como surgiu meu interesse por este tema? } \\
\text { É um tema original? Relevante? Viável? } \\
\text { Qual é a importância de estudar o } \\
\text { problema delimitado? Que contribuições } \\
\text { este estudo poderá trazer? }\end{array}$ & \\
\hline Identificação de objetivos & $\begin{array}{l}\text { Que objetivos pretendo alcançar com a } \\
\text { realização da pesquisa? }\end{array}$ & \\
\hline Definição do objeto da pesquisa & $\begin{array}{l}\text { Que pergunta explicita meu objeto de } \\
\text { estudo? }\end{array}$ & \\
\hline
\end{tabular}


O passo seguinte - Ferramenta 3: Escolhas teóricas — reflete os movimentos anteriores, envolvendo a elaboração das questões norteadoras, hipóteses ou pressupostos e os eixos teóricos que orientarão a pesquisa.

\section{FERRAMENTA 3}

Escolhas teóricas $\rightarrow$ eixos analíticos

\begin{tabular}{|c|c|c|}
\hline PASSO & INDAGAÇÃO & $\begin{array}{l}\text { RESPOSTA } \\
\text { PRELIMINAR }\end{array}$ \\
\hline $\begin{array}{l}\text { Elaboração de questões } \\
\text { norteadoras }\end{array}$ & $\begin{array}{l}\text { Que variáveis são fundamentais para } \\
\text { analisar meu problema de pesquisa? } \\
\text { Que perguntas constituem as } \\
\text { problematizações auxiliares em relação a } \\
\text { meu objeto de pesquisa? }\end{array}$ & \\
\hline $\begin{array}{l}\text { Construção de hipóteses ou } \\
\text { pressupostos }\end{array}$ & $\begin{array}{l}\text { Que tipo de resposta pretendo alcançar? } \\
\text { (perspectiva de validar, refutar ou ampliar } \\
\text { possibilidades de análise) } \\
\text { Que respostas posso antecipar em relação } \\
\text { às questões formuladas? }\end{array}$ & \\
\hline $\begin{array}{l}\text { Definição do marco teórico que } \\
\text { orientará a pesquisa }\end{array}$ & $\begin{array}{l}\text { A que teorias devo recorrer para } \\
\text { fundamentar minha pesquisa? } \\
\text { Quais são meus principais eixos de } \\
\text { análise? Que categorias devo utilizar? }\end{array}$ & \\
\hline
\end{tabular}

A Ferramenta 4: Escolhas metodológicas trabalha com os caminhos a serem percorridos, em estreita sintonia com os eixos teóricos escolhidos. Nesse momento pensamos nos métodos, nos instrumentos para coleta de dados, nos sujeitos a serem pesquisados, na análise e interpretação do material empírico, na devolução do conhecimento construído... 


\section{FERRAMENTA 4}

Escolhas metodológicas $\rightarrow$ caminhos

DESAFIO: “A solução para o problema é o caminho que o levará de onde você está até onde você deseja ir [...] os dados conhecidos me dão tijolos para construir a casa. Mas eu não construirei casa alguma se não organizar os tijolos segundo a imagem de uma entidade ainda inexistente: a casa [...]. A habilidade não é feita pela ferramenta. Espingardas não fazem caçadores, caniços não fazem pescadores, algemas não fazem detetives, laboratórios não fazem cientistas [...]. O que torna certos indivíduos caçadores, pescadores [...] é o conhecimento que eles possuem daquela entidade, bicho, peixe ou gente que, mais cedo ou mais tarde, terão de pegar. Este conhecimento se constitui numa teoria - o que lhes permite prever os movimentos da presa" (Alves, 1966, passim).

\begin{tabular}{|c|c|c|}
\hline PASSO & INDAGAÇÃO & $\begin{array}{c}\text { RESPOSTA } \\
\text { PRELIMINAR }\end{array}$ \\
\hline Definição da metodologia & $\begin{array}{l}\text { Que metodologia vai orientar a execução } \\
\text { de minha pesquisa? Por quê? }\end{array}$ & \\
\hline $\begin{array}{l}\text { Identificação do universo e } \\
\text { amostra }\end{array}$ & $\begin{array}{l}\text { Em que cenário/contexto a pesquisa vai ser } \\
\text { realizada? Como ter acesso a ele? } \\
\text { Fontes de informação: quais e quantas? } \\
\text { Critérios para a seleção dessas fontes? }\end{array}$ & \\
\hline $\begin{array}{l}\text { Seleção de instrumentos de } \\
\text { coleta de dados, eixos de análise } \\
\text { e registros }\end{array}$ & $\begin{array}{l}\text { Que instrumentos, de coleta de dados devo } \\
\text { utilizar? Motivos? Como? } \\
\text { Devo realizar o pré-teste e a verificação } \\
\text { interna? } \\
\text { Que eixos analíticos comporão meus } \\
\text { instrumentos? } \\
\text { Como vou registrar as informações? }\end{array}$ & \\
\hline $\begin{array}{l}\text { Análise dos dados coletados e } \\
\text { divulgação dos resultados }\end{array}$ & $\begin{array}{l}\text { Que tipo de análise pretendo fazer? } \\
\text { Que recursos devo utilizar? Gráficos, } \\
\text { tabelas? Análise de conteúdo? } \\
\text { Como posso organizar a interpretação dos } \\
\text { dados? Como "devolvê-los"? }\end{array}$ & \\
\hline
\end{tabular}

Por último, a Ferramenta 5: Recursos, tempo e normas, nos lembra que não basta termos delimitarmos bem um tema, desenhando-o em um contexto teórico-metodológico. Precisamos também pensar nos diferentes recursos necessários para a viabilização do projeto, além de planejarmos o uso do tempo. Aqui incluímos ainda a necessidade de recorrermos às normas técnicas para a elaboração de trabalhos científicos. 


\section{FERRAMENTA 5}

Recursos, tempo e normas

\begin{tabular}{|c|c|c|}
\hline PASSO & INDAGAÇÃO & $\begin{array}{c}\text { RESPOSTA } \\
\text { PRELIMINAR }\end{array}$ \\
\hline $\begin{array}{l}\text { Indicação dos recursos humanos, } \\
\text { materiais e financeiros }\end{array}$ & $\begin{array}{l}\text { Que recursos serão necessários para a } \\
\text { realização do projeto? Fontes de } \\
\text { financiamentos? }\end{array}$ & \\
\hline Elaboração de um cronograma & $\begin{array}{l}\text { Em que período a pesquisa será realizada? } \\
\text { Como distribuir as etapas dentro do tempo } \\
\text { previsto? }\end{array}$ & \\
\hline $\begin{array}{l}\text { Revisão das referências } \\
\text { bibliográficas }\end{array}$ & $\begin{array}{l}\text { Que material bibliográfico devo relacionar? } \\
\text { Normas técnicas? }\end{array}$ & \\
\hline $\begin{array}{l}\text { Organização de anexos e } \\
\text { apêndices }\end{array}$ & $\begin{array}{l}\text { Anexos? Apêndices? Quais? } \\
\text { Necessidade? Importância? }\end{array}$ & \\
\hline
\end{tabular}

Esse conjunto de ferramentas encontra-se em fase de experiência há pouco mais de um ano, indicando, até o momento, a validade de seu uso para fins didáticos, sobretudo porque os acadêmicos são sujeitos proativos de sua aprendizagem. O exercício que acontece passo a passo, sem perder a perspectiva do todo, tem propiciado o desenvolvimento de reflexões, questionamentos e sistematizações, por meio de uma expressiva interatividade aluno-aluno, aluno-professor e aluno-assistente social supervisor de estágio. Nessa experiência destaca-se, ainda, a importância do diálogo realidade empírica-eixos teóricos selecionados, numa via de mão dupla, bem como se identifica e valoriza a estreita relação entre o saber e o fazer.

Mesmo assim, tais ferramentas encontram-se em permanente avaliação, comportando alterações de acordo com as temáticas e sujeitos trabalhados, não cabendo seu entendimento como modelo fechado a ser seguido. 


\section{Palavras finais}

É certo que nossa prática às vezes abala nossas certezas, levando-nos a duvidar da possibilidade de provocar alguma mudança no perverso cotidiano que nos cerca. Mas, ela é também uma prática que nos desafia, nos instiga a pensar de novo e nos leva a insistir na luta para vencermos nossas fragilidades, em âmbito micro e macroestrutural, na tentativa de encontrarmos outros caminhos, fortalecendo as bases para perseguirmos nossas utopias.

Nesse sentido, acreditamos que se muitos são os caminhos a ser trilhados, não podemos nos esquecer que tão importante quanto pensar é decidir o que vamos fazer com as nossas reflexões. Localizar onde estamos e onde queremos chegar, conhecer para mudar - este é o ponto fundamental. Para tanto, não vemos outro caminho que não aquele onde a pesquisa seja assumida como movimento fundamental e permanente, tanto durante a formação profissional, quanto durante o exercício profissional do assistente social.

Ao olharmos a história de nossa profissão, não há como deixar de perceber que nós, assistentes sociais, somos autores e atores em toda a trajetória já percorrida. Não há como não admitir, portanto, nossa responsabilidade, não só em torno do ser, mas também no que se refere ao vir a ser do Serviço Social.

Se nessa trajetória queremos marcar posições cada vez mais sólidas e competentes; se insistimos em nosso compromisso com os valores humano-genéricos assumidos em nosso projeto ético-político; se valorizamos nossa experiência cotidiana e entendemos a importância dos movimentos de CONSTRUÇÃO — DESCONSTRUÇÃO — RECONSTRUÇÃO — PROPOSIÇÃO, não há como fugir do reconhecimento que

não vale sacralizar a prática. Teoria e prática detêm a mesma relevância científica e constituem no fundo um todo só. Uma não substitui a outra e cada qual tem sua lógica própria. Nos extremos, os vícios do teoricismo e do ativismo causam os mesmos males. Não se pode realizar prática criativa sem retorno constante à teoria, bem como não se pode fecundar a teoria sem confronto com a prática. (Demo, 1991, p. 27)

E ainda:

A pesquisa é um dos procedimentos teórico-metodológicos que, ao ser incorporado à prática profissional, poderá levar o assistente social a se reinventar, recons- 
truir e até construir um vir a ser para o Serviço Social, a partir da eliminação da consciência acomodada e até adormecida. (Setúbal, 2007, p. 70)

Incansavelmente falamos dos novos tempos em que vivemos e lutamos por um maior reconhecimento de nossa profissão. Incansavelmente também devemos assumir a pesquisa como elemento imprescindível ao cotidiano do Serviço Social, para que possamos imprimir a marca da competência a nosso exercício profissional.

Artigo recebido em mar./2010 - Aprovado em jun./2010

\section{Referências bibliográficas}

ALVES, Rubem. Filosofia da ciência: introdução ao jogo e suas regras. São Paulo: Ars Poética, 1996.

Pesquisa: para quê? s/d. Mimeo.

ALVES-MAZZOTTI, A. J.; GEWANDSZNAJDER, F. O método nas ciências naturais e sociais: pesquisa qualitativa e quantitativa. São Paulo: Pioneira, 1998.

AQUINO, Eudes de Freitas. Um velho Brasil estatístico e o novo demografismo social. Aliança em revista. Brasília, v. 2, n. 6, p. 12-13, jun.-jul. 2001.

BARBIANI, Rosangela. Sobre o ato de conhecer e o conhecer em ato... onde está o sujeito da frase? In: Encontro Nacional de Pesquisadores em Serviço Social, 9, 2004. Anais... Porto Alegre: Abepess. CD-ROM.

CARDOSO, Ciro Flamarion. Como elaborar um projeto de pesquisa. [1998]. Mimeo.

CROSSEN, Cynthia. O fundo falso das pesquisas: a ciência das verdades torcidas. Rio de Janeiro: Revan, 1996. 278 p.

DA MATA, Roberto. O ofício de etnólogo ou como ter "anthropological blues". In: NUNES, Edson de Oliveira (Org.). A aventura sociológica. Rio de Janeiro: Zahar Editores, 1978. p. 23-35.

DEMO, Pedro. Pesquisa: princípio científico e educativo. São Paulo: Cortez, 1991.

DENZIN, Norman; LINCOLN, Yvonna. Handbook of qualitative research. 2. ed. Califórnia: Sage Publications, 2000. 
ECO, Umberto. Como se faz uma tese. 14. ed. São Paulo: Perspectiva, 1977. 170 p. FALEIROS, Vicente de Paula. Serviço Social: questões presentes para o futuro. Serviço Social \& Sociedade, São Paulo, v. 17, n. 50, p. 9-39, abr. 1996.

FREITAS, Maria Éster de. Viva a tese! Um guia de sobrevivência. 2. ed. Rio de Janeiro: Fundação Getúlio Vargas, 2002. 107 p.

IAMAMOTO, Marilda. O Serviço Social na Contemporaneidade: trabalho e formação profissional. São Paulo: Cortez, 1998.

LEFEBVRE, Henri. A vida cotidiana no mundo moderno. São Paulo: Ática, 1991. 216 p.

MARTINELLI, Maria Lúcia. Pesquisa qualitativa: elementos conceituais e teórico-metodológicos. Encontro de Pesquisadores do Instituto de Ciências da Sociedade e Desenvolvimento Regional. Campos dos Goytacazes, n. 1, p. 8-15, out. 2005.

MILLS, Charles Wright. A imaginação sociológica. 6. ed. Rio de Janeiro: Zahar, 1982. $246 \mathrm{p}$.

MORIN, Edgar. A religação dos saberes: o desafio do século XXI. Rio de Janeiro: Bertran Brasil, 2001.

NUNES, Edson de Oliveira (Org.). A aventura sociológica. Rio de Janeiro: Zahar Editores, $1978.331 \mathrm{p}$.

RESENDE, Otto Lara. Vista cansada. Folha de S.Paulo. 23 fev. 1992. Disponível em: $<$ http://www.releituras.com/olresende_vista.asp >. Acesso em: 18 fev. 2010.

SETÚBAL, Aglair Alencar. Desafios à pesquisa no Serviço Social: da formação acadêmica à prática profissional. Katálysis. Florianópolis, v. 10, n. esp. p. 64-72, 2007.

VELHO, Gilberto. Observando o familiar. In: NUNES, Edson de Oliveira (Org.). A aventura sociológica. Rio de Janeiro: Zahar Editores, 1978. 331 p., cap. 2, p. 36-46. 